\title{
Erratum to: Increasing quasiconcave co-radiant functions with applications in mathematical economics
}

\author{
Juan Enrique Martínez-Legaz ${ }^{1}$
}

Published online: 26 July 2017

(C) Springer-Verlag Berlin Heidelberg 2017

\section{Erratum to: Math Meth Oper Res (2005) 61:261-280 DOI 10.1007/s001860400405}

I am grateful to Abelardo Jordán (Pontificia Universidad Católica del Perú) and Lludy Eladia Missa Franco (Universidad San Luis Gonzaga de Ica) for having kindly pointed out to me some errors, which can be corrected as follows:

(1) On p. 265, the 4th and 5th lines after the displayed formula (5) should read

$$
\begin{aligned}
u^{\downarrow}(\lambda x, x) & \left.=\limsup _{t \rightarrow+0} \frac{1}{t}(u((\lambda+t) x))-u(\lambda x)\right) \\
& =\limsup _{t \rightarrow+0} \frac{1}{\lambda} \frac{\lambda}{t}\left(u\left(y+\frac{t}{\lambda} y\right)-u(y)\right)=\frac{1}{\lambda}\left(\left(\phi_{y}\right)_{+}^{\prime}(1)+\phi_{y}(1)\right) .
\end{aligned}
$$

(2) On p. 265, in the 7th line after the displayed formula (5) delete the expression "- $\phi_{y}(1)$ " appearing in the numerator of the last fraction.

(3) On p. 273, replace "inverse co-radiant" by "radiant" in the second line of the statement of Theorem 15 and in lines 5 and 8-9 of the proof of this theorem.

(4) On p. 278, replace "inverse co-radiantness" by "radiantness" in line 32.

The online version of the original article can be found under doi:10.1007/s001860400405.

$凶 \quad$ Juan Enrique Martínez-Legaz

JuanEnrique.Martinez.Legaz@uab.cat

1 Departament d'Economia i d'Història Econòmica, Universitat Autònoma de Barcelona, 08193 Bellaterra, Spain 